\title{
Oscillation damping in the power unit when starting the engine equipped with the Common Rail system
}

\author{
Igor Taratorkin ${ }^{1,2, *}$, Victor Derzhanskii ${ }^{1,2}$, and Alexander Taratorkin ${ }^{1}$ \\ ${ }^{1}$ IES UB RAS, Department of Transportation Vehicles Mechanics, 620049, Ekaterinburg, Russia \\ ${ }^{2} \mathrm{KSU}$, Kurgan State University, Department of Applied Mechanics 640020, Kurgan, Russia
}

\begin{abstract}
The paper studies formation of the power-train elements dynamic loading at engine starting, shows the results of experiments and of simulation modeling and substantiates the ways of reducing dynamic loading of the mechanical system under study.
\end{abstract}

\section{Introduction}

Dynamic loading of transport vehicles power-train unit (PTU) in steady operating modes is determined by resonance oscillations excited by the harmonic components of engine torque when perturbation and natural frequencies of the mechanical system coincide. Taking resonance oscillation out of the operating bandwidth of engine shaft speeds can be provided by selecting stiffness $\mathrm{C}$ or momentum of inertia $J_{\text {пр }}$ [1-4]. In the power-train unit of many transport vehicles with hydro-mechanical transmission, with TC (torque convertor) cast wheels, the torsion shaft performs the function of an elastic element - a torsional damper. The torsion shaft is installed between the engine flywheel and the torque converter impeller. This solution allows for increasing specific volumetric power of the enginetransmission compartment in comparison with foreign designs. However, Taking resonance oscillations out of the engine revolutions operating range does not exclude their excitation at low frequencies - when the engine starts and stalls [5]. Taking into consideration high energy consumption capacity of the process, there arises a problem of ensuring elastic element (torsion shaft) durability. Calculation studies of torsional oscillations in transport vehicle transmissions in Russia began in the 1950-60s. As fundamentals, the works of Terskikh V.P. [6], Burtsev S.E. [7], Veits V.L., Kochura A.E. [8], Grishkevich A.I.[9] et al. were accepted. These works were the basis for development of the method for calculating stationary torsional oscillations excited by an internal combustion engine. On their basis in VNIITransmash (Mobile Vehicle Engineering Institute), the industry standard was developed, which is widely used today. Research works of Zaitsev V.A., Zhuchkov M.G. et al. are devoted to the problems of dynamic loading research, forecast and its reduction, problems of torsion shafts durability for vehicles with traditional engines, problems of torque oscillation damper engineering design for transport vehicle transmissions. The effect of excitation of resonance oscillations is especially acute when the engine with

*Corresponding author: ig_tar@mail.ru 
modern intelligent mechatronic fuel control systems (Common Rail) is started. Development of perspective power-train plants requires development of new control algorithms and their software implementation. In accordance with the abovementioned, the subject of investigation is a PTU comprising HMT (hydro mechanical transmission) and a diesel engine with Common Rail, an intelligent mechatronic fuel control systems. The work objective is to study the process of PTU element dynamic loading at engine starting and development of recommendations on its reduction.

For evaluating and analyzing dynamic loads in the engine starting mode, it is necessary to create a model that takes into account a real state, system elements properties, including nonlinearity of the elastic and dissipative damper characteristics. Considering parameter ambiguity in the numerical modeling of the starting process, it is necessary to apply a large number of assumptions. In this regard, kinematic and power functions in time domain are determined experimentally by the diagnostic CAN-bus of the information-measuring and engine control system. Fig. 1, 2 show the parameter behavior of the engine equipped with such a system - shaft rotary speed, its calculated moment, cyclic fuel feed and injection lead angle.

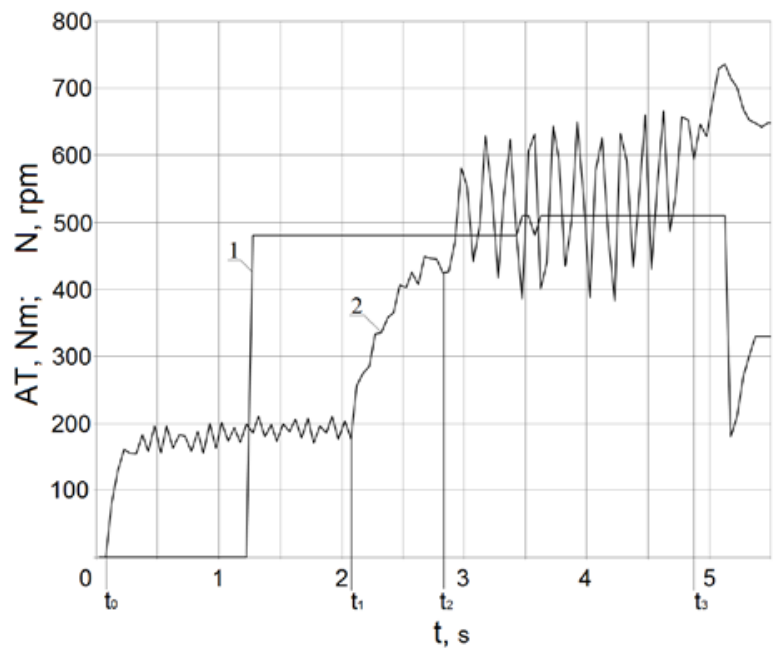

Fig. 1. Fragment of the oscillogram with recorded actual torque (1) and shaft speed (2) in start and idle modes

During the time period from 0 to t1 (Figure 1), the starter rotates the engine shaft until reaching the starting frequency $(18 \ldots 22 \mathrm{rad} / \mathrm{s})$ without fuel feed. After that, at $t_{1} \leq t<t_{2}$, the fuel feed begins to start the engine and within $0.7 \ldots 0.8 \mathrm{~s}$ an intensive increase in rotary speed of the engine shaft occurs. Further on, when the third motor harmonics of the engine torque coincides with the natural frequency of the mechanical system, the engine shaft resonance oscillations are excited at frequency of $26 \ldots 28 \mathrm{~Hz}$. This leads to deceleration of engine acceleration. It should be noted that the report rate of the shaft rotary speed sensor SAE J1939-71 is $20 \mathrm{~Hz}$ with the required minimum report rate $60 \mathrm{~Hz}$, in compliance with the Kotelnikov theorem [10]. Hence, the oscillatory process can be regarded as a qualitative exemplification. In order to correctly determine the oscillation frequency in the range exceeding the capability of the CAN bus (according to the report rate), oscillations of the output pulses of the in-built induction engine speed sensor of the engine crankshaft were recorded alongside the CAN bus in an analog mode. 


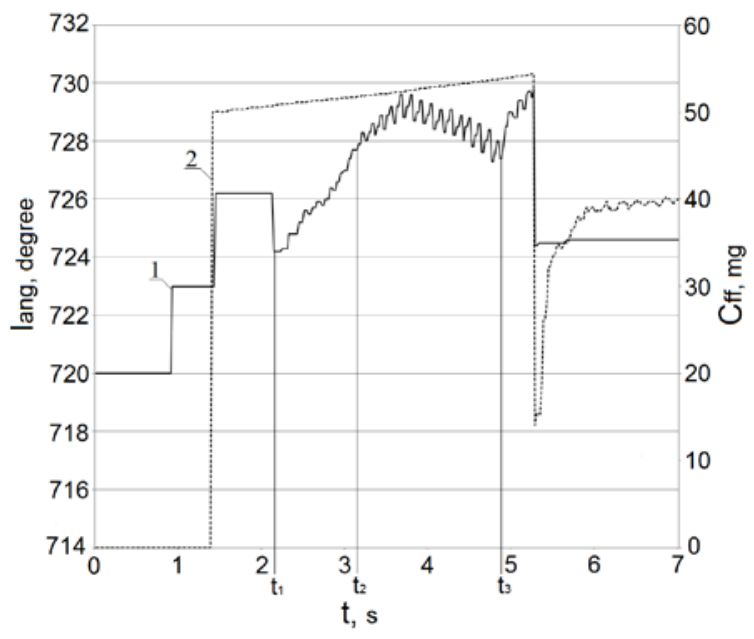

Fig. 2. Fragment of the oscillogram with the recorded injection lead angle of the basic pulse (1) and cyclic fuel feed (2) in start and idle modes

High report rate allows for fixing irregularity in crankshaft rotary speed and, applying cyclic functions of the applied software [11,12], for carrying out selection of harmonic components of the investigated oscillatory process. In the case under consideration, these are resonance oscillations at natural frequency of the mechanical system coinciding with the third motor harmonics. The described process continues for $1.5 \ldots 2.0 \mathrm{~s}$ up to time $t_{3}$. At that, the moment comprises a constant component and a dynamic component with a significant amplitude $M_{\text {dyn }}=J_{\text {red }} A \dot{\omega}^{2}$ (at $\varphi=6 \ldots 7$ degrees $M_{\text {dyn }}$ is $\sim 3 \ldots 4 k N m$ ), and rotary acceleration reaches values of $1500 \ldots 3000 \mathrm{rad} / \mathrm{s} / \mathrm{s}$.

During oscillations, the cyclic fuel feed remains unchanged (Fig. 2) and insufficient to continue the engine acceleration. Due to an increase in the required level of energy consumption, an average engine shaft speed in this mode does not increase fast enough (the acceleration of passing through the resonance zone does not exceed $8.5 \mathrm{rad} / \mathrm{s} / \mathrm{s}$.) After the rotary speed exceeds the resonance zone, its value rises sharply and reaches the value of the idle movement ( $\mathrm{n}=750 \mathrm{rpm})$. Due to the irregularity of engine shaft speed, the algorithm of the fuel feed system is broken. At the same time, with a phase shift, the system regulates the injection angle and cyclic fuel feed, which further destabilizes the process. In the future, the cyclic feed is stabilized at the level corresponding to the idling speed.

Excitation of energy-consuming torsion shaft resonance oscillations during starting the engine with a modern intelligent mechatronic system prolong the starting process as a result of electronic system freeze-up - an occurrence of the so-called «data collision» [13]. In this case, accumulation of the number of mechanical system loading cycles in the resonance mode occurs, including an elastic element, the torsion shaft. This mode is an off-design mode and leads to torsion destruction.

In work [5], the process of starting a classic diesel engine (with a traditional fuel feed system) was studied in detail. The author established the dependence of the maximum torsion shaft dynamic loads on the acceleration of passing through the resonance. As follows from the author's findings, as the acceleration of passing through the resonance zone increases, the level of maximum dynamic loads on the torsion shaft is reduced by 10 ... $20 \%$ compared to the stationary mode of resonant oscillations (with the system natural frequency coinciding with the third harmonics of the diesel). In this case, the range from 50 to $200 \mathrm{rad} / \mathrm{s} / \mathrm{s}$ is investigated. 
In the case under consideration, the acceleration of resonance zone passing lies in the range from 6 to $8.5 \mathrm{rad} / \mathrm{s} / \mathrm{s}$, i.e. the start occurs under extremely unfavorable conditions (in the time interval from $t_{2}$ to $\left.t_{3}\right)$ ) and the mechanical system is, actually, in the state of resonance in the steady mode. It should be noted that the level of implemented resonance loads depends significantly on mechanical system acceleration and varies widely, determined by the engine thermal state by means of its starting (by an electric starter or by a pneumatic system).

\section{Calculation scheme and simulation model}

The findings make it possible to develop a mathematical model for analyzing possibilities of reducing the elastic shaft dynamic loading. Fig. 3 shows a computational scheme. The computational scheme is presented in the form of two inertia masses - of the flywheel with the momentum of inertia $J_{d}$ and the momentum of inertia of the pump impeller with the momentum of inertia $J_{n}$, connected with each other by elastic-dissipative nonlinear coupling with rigidity $\mathrm{C}=29 \mathrm{kNm} / \mathrm{rad}$ and by the moments of preload $M_{\mathrm{pr}}=0,35 \mathrm{kNm}$ and by the momentum friction $M_{\mathrm{fr}}=0,33 \mathrm{kNm}$.. The motion of a two-mass system is described by second-order differential equations:

$$
\begin{gathered}
J_{d} \ddot{\varphi}+M(\varphi, \dot{\varphi})=M_{i c e} \\
J_{n} \ddot{\varphi}-M(\varphi, \dot{\varphi})=0
\end{gathered}
$$

where $M(\varphi, \dot{\varphi})$ is an elastic moment, which is the function of the twist angle of the shaft $\varphi$ and of the relative displacement speed $\dot{\varphi}$, taking into account the phenomenon of nonlinearized «dry» friction of the oscillation damper; $M_{i c e}$ is the polyharmonic engine disturbance torque. The simulation model, performed in the LMS Amesim package [14], is shown in Fig. 4.

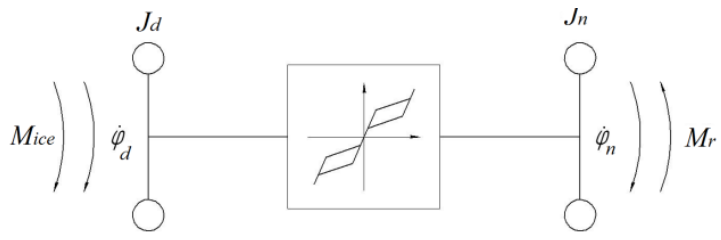

Fig. 3. Computational scheme of the dynamic system

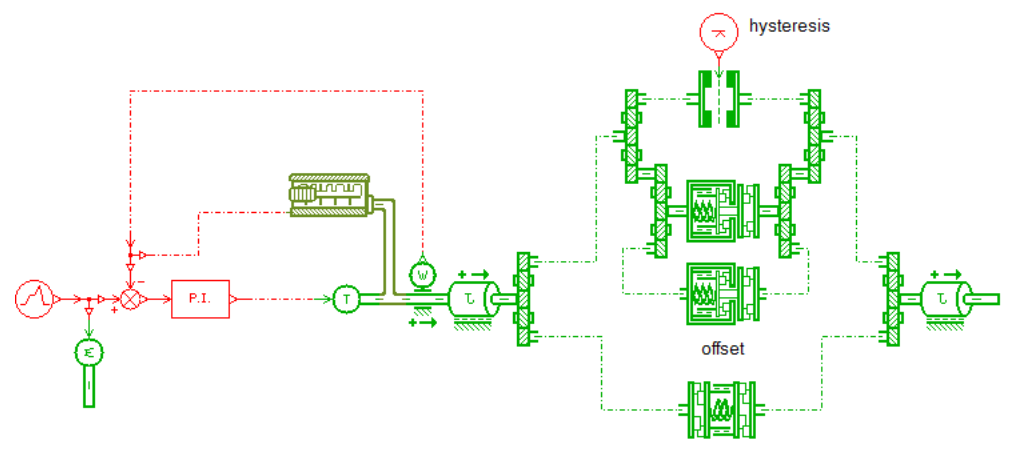

Fig. 4. Simulation model of the dynamic system for researching the process of engine starting 
The model comprises the control unit (allows for setting engine acceleration during the starting), the engine unit as a source of a perturbing moment that allows for specifying periodic and constant components; the torsional oscillation damper unit and dynamical system inertial masses proper.

\section{Results of simulation modeling}

The modelling results for various acceleration algorithms in the starting process are tabulated in Table 1 and are shown in Fig. 5.
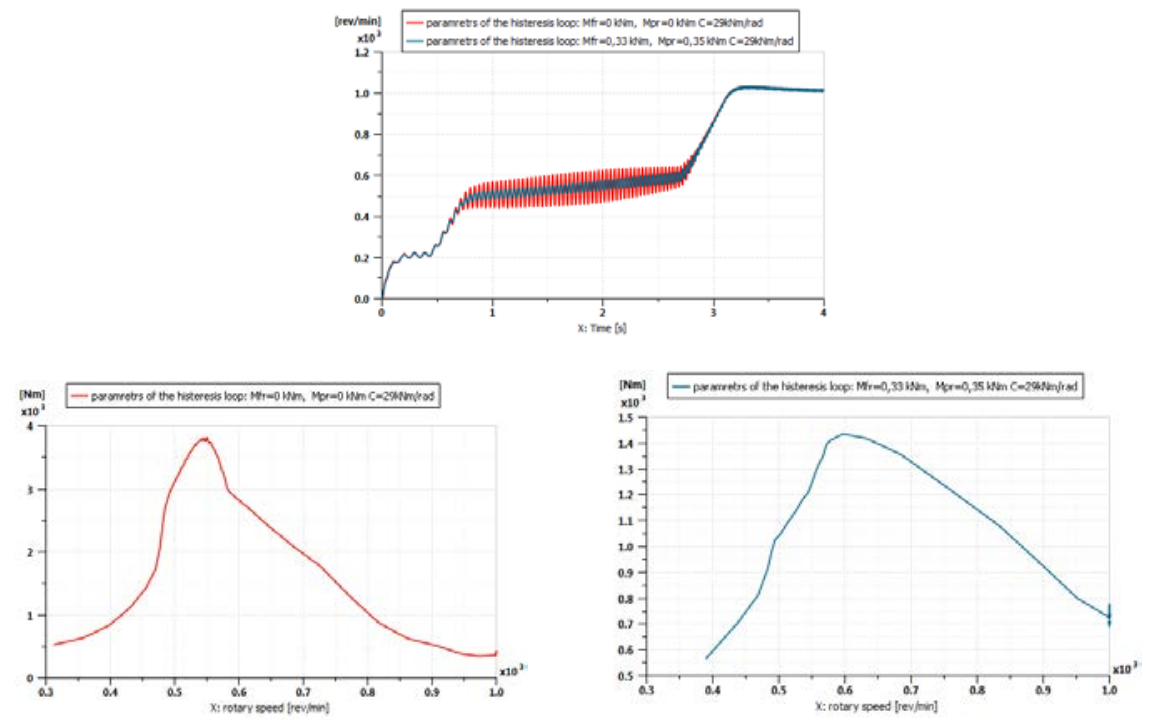

$6 \mathrm{rad} / \mathrm{s} / \mathrm{s}$
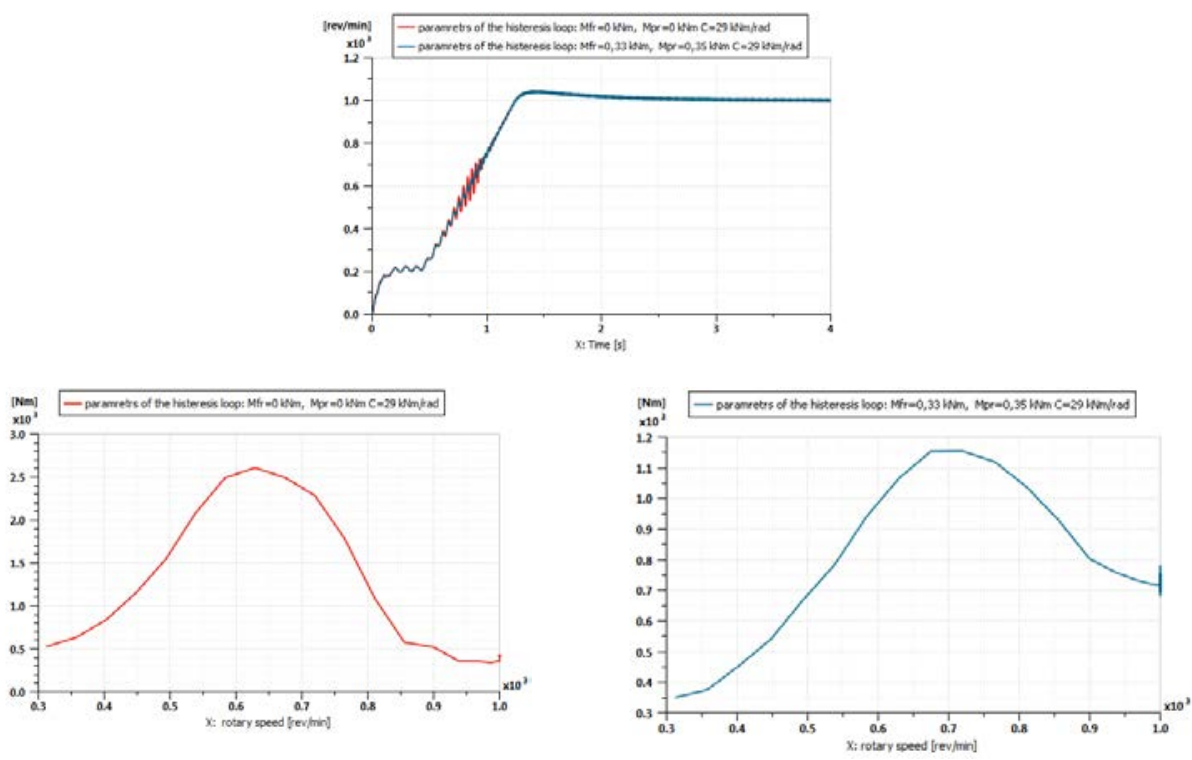

$100 \mathrm{rad} / \mathrm{s} / \mathrm{s}$

Fig. 5. The modelling results for various acceleration algorithms in the starting process 
The findings of the computational experiment performed for the mechanical system under study show that the decrease in the dynamic moment can be even more significant than that given in [5]. This is due to lower values of the resonance frequency and the order of the fundamental motor harmonics of the engine (resonance frequency $26 \ldots 28 \mathrm{~Hz}$ instead of $52 \ldots 56 \mathrm{~Hz}$ and the third fundamental motor harmonics instead of the sixth).

Table 1. Results of mechanical system dynamic load modelling at engine starting

\begin{tabular}{|c|l|c|c|c|}
\hline № & \multicolumn{1}{|c|}{ Dynamic system parameters } & \multicolumn{3}{|c|}{ Moment amplitude $\mathrm{kNm}^{\mathrm{k}}$} \\
\hline & $\begin{array}{l}\text { Rotary acceleration at starting } \dot{\omega}, \\
\text { rad/s/s }\end{array}$ & 6 & 50 & 100 \\
\hline 1 & $\begin{array}{l}\text { Rigidity C }=29, \mathrm{kNm} / \mathrm{rad} \\
\text { Parameters of the hysteresis loop } \\
M_{f r}=0, M_{p r}=0\end{array}$ & 3,75 & 3,2 & 2.6 \\
\hline 2 & $\begin{array}{l}\text { Rigidity C }=29, \mathrm{kNm} / \mathrm{rad} \\
\text { Parameters of the hysteresis loop } \\
M_{f r}=0,33 \mathrm{kNm}, M_{p r}=0,35 \mathrm{kNm}\end{array}$ & 1,44 & 1,27 & 1,15 \\
\hline
\end{tabular}

Thus, the findings suggest that the main way to reduce mechanical system dynamic loading at starting the engine with a modern fuel control system is a valid adjustment of the control system algorithm in the "start" mode, which ensures fast acceleration when passing through a dangerous resonance zone.

\section{Conclusions}

1) One of the possible ways to reduce mechanical system dynamic loading at starting the engine with a modern fuel control system is a valid adjustment of the control system algorithm in the "start" mode, which ensures fast acceleration when passing through a dangerous resonance zone.

2) Reduction of the dynamic loading of the power-train unit at engine starting can be achieved by introducing a damping device into the engineering design, for example, in the form of a friction-type clutch located between the flywheel and the pump impeller of the torque converter. The required effect can also be achieved by shifting the resonance frequency to the values $23 \ldots 24 \mathrm{~Hz}(450 \ldots 460 \mathrm{rpm})$. This can be achieved by reducing the diameter of the torsion shaft when excluding «data collision».

3) Taking into account that engine starting requires significant power input to actuate the power-train unit and other power consumers, it seems advisable to disconnect them during the starting period. In this case, it is necessary to take into account a mechanical system natural frequency increase and, accordingly, a danger of natural frequency displacement into the engine idle speed zone.

This study was funded by the program of the President of the Russian Federation for the support of young scientists - Grant MK-5809.2018.8, and also with partial support under the state task IES UB RAS No. 0391 - 2014 - 007.

\section{References}

1. Reik, W. Albers, A. Schnurr, M. u.a.:Torque Control Isolation (TCI) The Smart Clutch. LuK-Symposium 1990. 
2. Albers, A.: Das Zweimassenschwungrad der dritten Generation - Optimierung der Komforteigenschaften von PKW-Antriebssträngen. Antriebstechnisches Kolloquium 91, Verlag TÜV-Rheinland, 1991.

3. Taratorkin A. Dynamic Loading Reduction of Multiplate Clutches Lined Plates of the Vehicle Powertrain / Taratorkin A. [et. al.] // SAE Technical Papers. SAE, 2014. №2014-01-2332. pp. 1 - 5 .

4. Taratorkin, A.I. [Reducing the dynamic load of friction clutches of hydro mechanical transmissions of transport vehicles]. Trudy NAMI: sb. Nauch. St. [Proceedings of NAMI: Sat. sci. art. Moscow: Nauka], 2015, Vol. 260, pp. 178 - 189. (in Russ.)

5. Beloutov G.S. [Mathematical model for calculating the dynamic loads in the input transmission elements during the passage of the resonance zone at engine starting]. Aktualnye problem zashchity I bezopasnosti: Trudy XVII Vserossijskoj nauchno prakticheskoj konferencii RARAN (1-4 aprelya 2014 g.). [Edition FBGU "Russian Academy of Missile and Artillery Sciences, Moscow], 2014, pp. 142 - 149. (in Russ.)

6. Terskikh V.P. Krutilnye kolebaniya valoprovoda silovyh ustanovok [Torsional oscillations of the power shaft of the power plants]. Leningrad: Shipbuilding, 1970.

7. Burtsev S.E. Raschet opasnyh rezhimov vynuzhdennyh kolebanij krutilnyh system gusenichnyh mashin [Calculation of dangerous modes of forced oscillations of torsional caterpillar systems]. Moscow, Publ. House of the Military Academy of Armored Forces, 1967.

8. Veits V.L., Kochura A.E. Dinamika mashinnyh agregatov s dvigatelyami vnutrennego sgoraniya [The dynamics of machine units with internal combustion engines]. Leningrad, Mechanical Engineering, 1976.

9. Grishkevich A.I. Proektirovanie transmissij avtomobilya [Design of transmissions of the car]. Moscow, Mechanical Engineering, 1983. 263 p.

10. Richard L. [Digital Signal Processing]. Translation from English. Leningrad, Richard. 2-nd edition, Moscow, OOO «Binom-Press» Publ., 2007.

11. PowerGraph [User guide], URL: http://www.powergraph.ru

12. Izmailov D.Yu. [PowerGraph. Part 2 - Carrying out measurements of PiCAD]. Moscow: Publ. MGU, 2008, No. 2, pp. 42-46

13. Control systems for diesel engines. Translation from German. C40. The first Russian edition. - Moscow, JSC «BPH» Driving», 2004. - 480 p.

14. LMS Imagine.Lab Model-oriented approach to designing mechatronic systems. URL: https://www.plm.automation.siemens.com/ru_ru/products/lms/imagine-lab/amesim 